\title{
THE USE OF LIGHTWEIGHT AGGREGATE IN PREPARATION OF THERMAL INSULATION LIME-BASED RENDERS
}

\author{
Jaroslav Pokorný*, Milena Pavlíková, ZByšek Pavlík \\ Czech Technical University in Prague, Faculty of Civil Engineering, Thákurova 7, 16629 Prague 6, Czech \\ Republic \\ * corresponding author: jaroslav.pokorny@fsv.cvut.cz
}

\begin{abstract}
Lime-based renders are common part of historical or older buildings that don't always provide a comfortable inside climate due to the problems with high thermal losses. Thermal insulation renders may possibly retrofit or replace original render layers and mitigate negative impacts of harmful external climate. In this respect, determination of basic structural, mechanical and thermal properties of lime-based renders containing various amount of perlite that was used as partial silica sand replacement is presented in the paper. Experimental tests performed for 28 days high relative humidity-cured samples showed significant decrease in bulk density and apparent density for renders with incorporated perlite compared to reference render mix composed of silica sand-based aggregate only. Accordingly, porosity of perlite mortars was significantly higher, what led to the lower thermal conductivity values in comparison with reference render. Although the mechanical resistance of perlite-modified renders was lower than that of reference material, it was still sufficient for their use as thermal insulation layer compatible with older construction materials. Based on the obtained data it can be concluded, the analysed hydrated lime-based plasters with perlite admixture can be considered as promising materials for buildings refurbishment.
\end{abstract}

KEYwords: Hydrated lime, perlite, renders, thermophysical properties.

\section{INTRODUCTION}

From historical point of view, rendering mortars have always been considered and applied as walls and building facades layers mainly serving to the masonry protection against weathering causing its gradual decay. Nevertheless, their decorative aspects were also of considerable importance to achieve aesthetical perfection 1, 2. Aerial lime plasters and mortars belong among the traditional building materials used for masonry and facades until late of the $19^{\text {th }}$ century. Lime was very often applied binder due to its ability to add plasticity and good workability to mortar mixture 3 . However, setting and hardening of pure lime mortars is a slow process because of its dependence mainly on reaction of calcium hydroxide with atmospheric carbon dioxide as shown in Eq. (1)

$$
\mathrm{Ca}(\mathrm{OH})_{2}+\mathrm{CO}_{2} \longrightarrow \mathrm{CaCO}_{3}+\mathrm{H}_{2} \mathrm{O} .
$$

On the other hand, the specific porous structure of lime mortars with high open porosity, usually ranging from 22 to $35 \%$, allows to pass a certain amount of moisture present in the masonry and thus keep the structure breathable [1, 4. Despite the protection and decorative aspects of traditional renders, their thermal conductivity is high compared to the EN 998-1 definition of a thermal insulation render $(\lambda \leq$ $0.20 \mathrm{~W} / \mathrm{mK}$ ) and varies typically in dry condition from 0.12 to $0.80 \mathrm{~W} / \mathrm{mK}[2,5]$.

The energy retrofitting of existing buildings should be considered as a reasonable approach to reduce the overall building energy consumption $\underline{6}$. As presented by Barbero-Barrera, facades are, among the thermal envelope components, the constructive system with the highest impact energy demand of buildings [7]. Most of buildings are made up of masonry with traditional renders which can be replaced or retrofit by thermal insulation renders made in the same way as those traditional. In production of thermal insulation renders, highly preferred possibility is adding of various types of mineral lightweight aggregates, such as vermiculite, zeolite, diatomite, perlite and pumice [6]. In this connection, Abidi et al. [8] tested plasters on gypsum basis containing perlite and vermiculite. Experimental results showed decrease of thermal conductivity up to $0.16 \mathrm{~W} / \mathrm{mK}$ from initial value $0.50 \mathrm{~W} / \mathrm{mK}$. Corbanaro et al. 9] presented similar observation for mortars containing natural hydraulic lime, Portland cement and perlite.

With regarding to the number of performed studies aimed at currently used renders, the influence of silica sand substitution with perlite on properties of traditional lime-based render is examined in the paper. Performed experiments pointed to the significant lightening of modified renders accompanied with improvement of their thermal insulation function. 


\begin{tabular}{ccccccc}
\hline Material & Specific surface & Bulk density & Apparent density & $d_{10}$ & $d_{50}$ & $d_{90}$ \\
\cline { 5 - 7 } & {$\left[\mathrm{m}^{2} / \mathrm{kg}\right]$} & {$\left[\mathrm{kg} / \mathrm{m}^{3}\right]$} & {$\left[\mathrm{kg} / \mathrm{m}^{3}\right]$} & & $\mu \mathrm{m}$ & \\
\hline Hydrated lime & $2211 \pm 25$ & $233 \pm 12$ & $2210 \pm 11$ & 0.8 & 4.2 & 50.3 \\
\hline
\end{tabular}

TABLE 1. Characteristics of lime hydrate CL 90-S.

\begin{tabular}{lccccc}
\hline \multirow{2}{*}{ Substance } & \multicolumn{5}{c}{ Content in kg/m ${ }^{3}$} \\
\cline { 2 - 6 } & M-R & MP 25 & MP 50 & MP 75 & MP 100 \\
\hline Hydrated lime & 326.1 & 336.5 & 364.6 & 384.6 & 408.1 \\
Sand 0.0/0.5 & 434.5 & 336.5 & 243.1 & 128.3 & - \\
Sand 0.5/1.0 & 434.5 & 336.5 & 243.1 & 128.3 & - \\
Sand 1.0/2.0 & 434.5 & 336.5 & 243.1 & 128.3 & - \\
Perlite EX 100 & - & 2.5 & 5.3 & 8.5 & 11.1 \\
Perlite PB 150 & - & 41.7 & 89.2 & 141.2 & 187.7 \\
Water & 391.3 & 319.7 & 266.0 & 200.0 & 134.3 \\
\hline
\end{tabular}

TABLE 2. Proportion of mortar mixes.

\section{EXPERIMENTAL}

\subsection{STUDIED MATERIALS AND SAMPLES PREPARATION}

As a fundamental binder component of mortar mixes, hydrated lime CL 90-S produced in factory Vápenka Čertovy chody Inc. (Lhoist S.A. group), Czech Republic, was used. Hydrated lime disposes very high purity and meets requirements of the standard EN 459-1 [10]. Basic properties and particle size distribution data of CL 90-S are summarized in Table 1.

A silica sand (Filtrační písky Ltd., Czech Republic) composed of three fractions $0.0 / 0.5 ; 0.5 / 1.0$ and $1.0 / 2.0 \mathrm{~mm}$ combined together in mass ratio $1 / 1 / 1$, was applied as reference aggregate. In modified render mixes, sand was partially or fully substituted with two commercially available types of perlite, EX 100 and $\mathrm{PB} 150$, mixed together in volume ratio $1 / 4$. Five types of mortar batches were prepared. Silica aggregate in reference mix M-R was replaced by lightweight aggregate in the amount of 25; 50; 75 and $100 \%$ by volume. The dosage of batch water corresponded to the value of spreading $160 \times 160 \pm 5 \mathrm{~mm}$ that was kept constant for all renders. Before adding, perlite mix was left in plastic box filled by water for 24 hours. Composition of particular mortar mixes is expressed in Table 2

From fresh render mixes, prisms having dimensions $40 \times 40 \times 160 \mathrm{~mm}$ and cubes with side of $70 \mathrm{~mm}$ were casted. In samples casting, the filled moulds were compacted by 5 hits on laboratory table. After 48 hours, the particular samples were unmoulded and stored for 26 days in conditions with high relative humidity of approx. $98 \%$ and at temperature of $20 \pm 1{ }^{\circ} \mathrm{C}$.

\subsection{PARTIClE SIZE Distribution}

Particle size distribution of hydrated lime was accessed using a laser diffraction particle size analyser Analysette 22 NanoTec (Fritsch) equipped with a red and green laser allowing to detect particles in diameter range from 0.08 to $2000 \mu \mathrm{m}$.

\subsection{SiEVING ANALYSIS}

Determination of particle size distribution of aggregates was performed according to the standard EN 933-1 11. At first, aggregate sample was dried at $105 \pm 5{ }^{\circ} \mathrm{C}$ to constant mass. Then, after natural cooling, the sample was placed into series of sieves with mesh size $2.0 ; 1.0 ; 0.5 ; 0.25 ; 0.125$ and $0.063 \mathrm{~mm}$ respectively, and mechanically shaken by vibratory sieve shaker Retsch AS 200.

\subsection{Pozzolanic ACTIVITy AND SPECIFIC SURFACE AREA}

Pozzolanic activity was studied for a finer type of perlite only. For its asseesment, modified Chapelle test according to the French norm NF P 18-513 was performed [12, 13]. The method is based on the reaction of $1 \mathrm{~g}$ of tested powder material with $2 \mathrm{~g} \mathrm{CaO}$ in water [13]. The value of aggregate specific surface was determined according to the standard EN 196-6 with the use of Blaine apparatus [13, 14.

\subsection{BASIC PHYSICAL PROPERTIES}

Studied renders were characterized by their basic structural properties such as bulk density, apparent density and total open porosity. The bulk density was measured according to the standard EN 1015-10 15 by weighing sample dry mass and determination of its volume by a digital calliper [16]. The apparent density was accessed using automatic helium pycnometer Pycnomatic ATC (Porotec). The total open porosity was calculated on the basis of knowledge of the bulk and apparent density values. The relative expanded uncertainty of applied testing method was $5 \%$ [16]. 


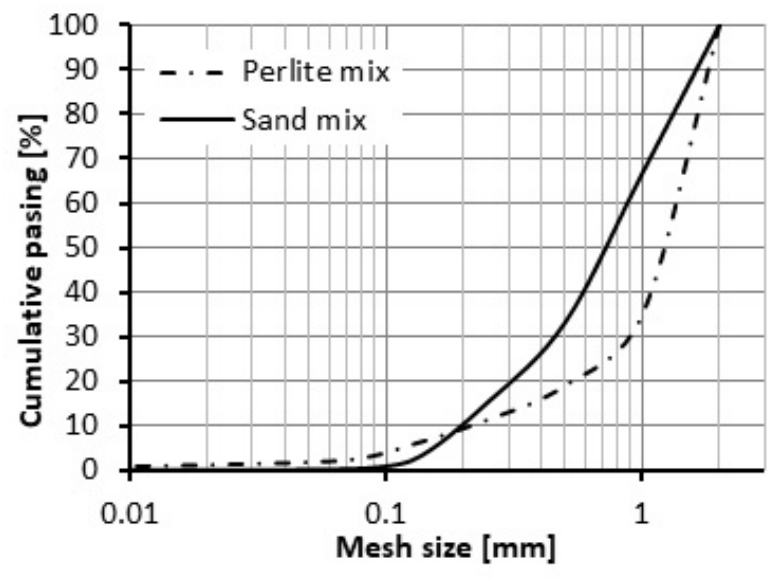

Figure 1. Sieve analysis of perlite and sand mix.

\subsection{Mechanical PROPERTies}

Among the mechanical properties, compressive strength, flexural strength and dynamic Young's modulus were examined. The strength tests were performed according to the standard EN 1015-11 [17]. The flexural strength was tested in a three point bending arrangement on standard prisms having dimensions of $40 \times 40 \times 160 \mathrm{~mm}$. The broken halves from the flexural strength tests were then used for determination of the compressive strength, whereas the loading area was $40 \times 40 \mathrm{~mm}$ [18]. The relative expanded uncertainty of the both strength tests was 1.4\%. The dynamic Young's modulus was measured by the pulse ultrasonic method (ASTM C597 - 16), using a DIO 562 device (Starman's Electronics) [19]. The expanded uncertainty of the dynamic Young's modulus determination was $2 \%$.

\subsection{TherMAL PROPERTIES}

The measurement of thermal parameters was conducted on a transient impulse method principle using device ISOMET 2114 (Applied Precision) equipped with surface circular probe [16]. The dried plaster samples in the form of cubes with side dimension of $70 \mathrm{~mm}$ were used for the measurement [16]. Additionally, thermophysical parameters of perlite mix, and silica aggregate in dependence on compaction time were tested. For the thermal conductivity $(\lambda)$ in the range $0.05-2.0 \mathrm{~W} / \mathrm{mK}$ was the measuring accuracy $10 \%$ of reading. For the volumetric heat capacity $(c)$ in the range $4.0 \times 10^{4}-4.0 \times 10^{6} \mathrm{~J} / \mathrm{m}^{3} \mathrm{~K}$, the measuring accuracy was $15 \%$ of reading [16].

\section{Results And Discussion}

Material characteristics of applied aggregates are given in Table 3. The reason for combination of two types of perlite was on the one hand to add more fine powder and gain smooth particle size distribution curve, as indicates Figure 1. On the other hand, perlite EX 100 (finer than PB 100) showed pozzolanic activity that could potentially support creation of a denser composite structure due to formation of hydrates of C-S-H type [20].

Thermophysical parameters of perlite mix, as well as silica aggregate in dependence on compaction time, are given in Table 4. From obtained data is clearly visible the high thermal conductivity of silica aggregate that is approx. 7.5 times higher compared to perlite. Accordingly, the volumetric heat capacity of silica aggregates was approx. 9 times higher than data obtained for perlite mix. With prolongation of compaction time, both the thermal conductivity and volumetric capacity increased as a consequence of minimization of air gaps between neighbouring aggregate grains. The procedure of this test simulated aggregate behaviour during mix casting and compaction. There is evident, after $20 \mathrm{~s}$ (sand) or $30 \mathrm{~s}$ (perlite mix) the values of the tested thermophysical parameters were practically stable.

The basic structural properties of studied plasters are shown in Table 5

Perlite incorporation resulted in a significant decrease in renders bulk and apparent densities. Accordingly, the increase in the total open porosity was quite apparent. These findings we assign to the low apparent density of perlite and porosity of embedded perlite particles. The total substitution of sand with perlite mix resulted in the one-third unit weight of render MP 100 compared to that measured for reference render. In general, data on structural properties were promising in the sense of improvement thermal insulation performance of perlite-modified renders because high porosity significantly retards heat transport due to the low thermal conductivity of dry air.

The mechanical resistance data measured on 28 days cured samples is summarized in Table 6 As expected, with increasing dosage of lightweight aggregate in render composition and thus with increase in renders porosity, gradual decline in all tested mechanical parameters was observed. The above mentioned assumption of contribution of pozzolanic activity of perlite EX 100 to creation of more-dense render structure was not confirmed, probably due to the low content of this pozzolana active material in the mix and limitation of contact of its particles with lime due to the presence of other fine and coarser aggregate particles. Quantitatively, the highest drop in both compressive and flexural strengths under 0.5 MPa exhibited render MP 100 , what is in agreement with its highest porosity.

Thermophysical properties measured on dried hardened cubic samples are given in Table 7 . Silica sand undeniably caused high thermal conductivity of reference render exceeding $1.3 \mathrm{~W} / \mathrm{mK}$. On the other hand, influence of porous lightweight aggregate on improvement of thermal insulation function of analysed materials was quite apparent. The higher the perlite content in the render mix, the lower the thermal conductivity of the sample. In fact, the total substitution of silica sand by perlite in tested render mixes resulted in the thermal conductivity even eleven times lower 


\begin{tabular}{cccc}
\hline Material & $\begin{array}{c}\text { Bulk density } \\
{\left[\mathrm{kg} / \mathrm{m}^{3}\right]}\end{array}$ & $\begin{array}{c}\text { Apparent density } \\
{\left[\mathrm{kg} / \mathrm{m}^{3}\right]}\end{array}$ & $\begin{array}{c}\text { Pozzolanic activity } \\
{\left[\mathrm{mg} \mathrm{Ca}(\mathrm{OH})_{2} / 1 \mathrm{~g}\right]}\end{array}$ \\
\hline Perlite EX 100 $(0.0 / 0.5)$ & $55 \pm 5$ & $651 \pm 5$ & 959 \\
Perlite PB 150 $(0.0 / 2.0)$ & $233 \pm 12$ & $572 \pm 4$ & - \\
Sand 0.0/0.5 & $1478 \pm 40$ & $2654 \pm 13$ & - \\
Sand 0.5/1.0 & $1505 \pm 45$ & $2648 \pm 13$ & - \\
Sand $1.0 / 2.0$ & $1568 \pm 50$ & $2640 \pm 12$ & - \\
\hline
\end{tabular}

TABLE 3. Material parameters of used aggregates.

\begin{tabular}{ccccccc}
\hline \multirow{2}{*}{$\begin{array}{c}\text { Time } \\
{[\mathrm{s}]}\end{array}$} & $\begin{array}{c}\text { Bulk density } \\
{\left[\mathrm{kg} / \mathrm{m}^{3}\right]}\end{array}$ & $\begin{array}{c}\lambda \\
{[\mathrm{W} / \mathrm{mK}]}\end{array}$ & $\begin{array}{c}c \times 10^{6} \\
{\left[\mathrm{~J} / \mathrm{m}^{3} \mathrm{~K}\right]}\end{array}$ & $\begin{array}{c}\text { Bulk density } \\
{\left[\mathrm{kg} / \mathrm{m}^{3}\right]}\end{array}$ & $\begin{array}{c}\lambda \\
{[\mathrm{W} / \mathrm{mK}]}\end{array}$ & $\begin{array}{c}c \times 10^{6} \\
{\left[\mathrm{~J} / \mathrm{m}^{3} \mathrm{~K}\right]}\end{array}$ \\
\hline 0 & $1657 \pm 25$ & $0.41 \pm 0.4$ & $1.57 \pm 0.24$ & $125 \pm 2$ & $0.05 \pm 0.01$ & $0.17 \pm 0.02$ \\
10 & $1910 \pm 28$ & $0.56 \pm 0.6$ & $1.68 \pm 0.25$ & $147 \pm 3$ & $0.06 \pm 0.01$ & $0.19 \pm 0.03$ \\
20 & $1916 \pm 29$ & $0.58 \pm 0.6$ & $1.68 \pm 0.25$ & $151 \pm 3$ & $0.06 \pm 0.01$ & $0.20 \pm 0.03$ \\
30 & $1922 \pm 22$ & $0.58 \pm 0.6$ & $1.68 \pm 0.25$ & $153 \pm 3$ & $0.06 \pm 0.01$ & $0.22 \pm 0.03$ \\
60 & $1927 \pm 22$ & $0.58 \pm 0.6$ & $1.69 \pm 0.26$ & $153 \pm 3$ & $0.06 \pm 0.01$ & $0.22 \pm 0.03$ \\
\hline
\end{tabular}

TABLE 4. Thermophysical properties of sand and perlite aggregate in dependence on compaction time.

\begin{tabular}{cccc}
\hline Material & $\begin{array}{c}\text { Bulk density } \\
{\left[\mathrm{kg} / \mathrm{m}^{3}\right]}\end{array}$ & $\begin{array}{c}\text { Apparent density } \\
{\left[\mathrm{kg} / \mathrm{m}^{3}\right]}\end{array}$ & $\begin{array}{c}\text { Total open porosity } \\
{[\%]}\end{array}$ \\
\hline M-R & $1756 \pm 26$ & $2598 \pm 13$ & $32.4 \pm 1.6$ \\
MP 25 & $1514 \pm 21$ & $2389 \pm 11$ & $36.6 \pm 1.8$ \\
MP 50 & $1216 \pm 18$ & $2101 \pm 11$ & $42.1 \pm 2.0$ \\
MP 75 & $945 \pm 13$ & $1835 \pm 9$ & $48.5 \pm 2.3$ \\
MP 100 & $617 \pm 9$ & $1378 \pm 7$ & $55.6 \pm 2.8$ \\
\hline
\end{tabular}

TABLE 5. Basic structural properties of studied renders.

\begin{tabular}{cccc}
\hline Material & $\begin{array}{c}\text { Flexural strength } \\
{[\mathrm{MPa}]}\end{array}$ & $\begin{array}{c}\text { Compressive strength } \\
{[\mathrm{MPa}]}\end{array}$ & $\begin{array}{c}\text { Young's modulus } \\
{[\mathrm{GPa}]}\end{array}$ \\
\hline M-R & $1.1 \pm 0.1$ & $1.3 \pm 0.1$ & $4.4 \pm 0.1$ \\
MP 25 & $0.8 \pm 0.1$ & $1.0 \pm 0.1$ & $3.3 \pm 0.1$ \\
MP 50 & $0.6 \pm 0.1$ & $0.9 \pm 0.1$ & $1.8 \pm 0.1$ \\
MP 75 & $0.5 \pm 0.1$ & $0.8 \pm 0.1$ & $1.4 \pm 0.1$ \\
MP 100 & $0.4 \pm 0.1$ & $0.4 \pm 0.1$ & $0.7 \pm 0.1$ \\
\hline
\end{tabular}

TABLE 6. Mechanical parameters of studied renders.

\begin{tabular}{cccc}
\hline Material & $\begin{array}{c}\text { Thermal conductivity } \\
{[\mathrm{W} / \mathrm{mK}]}\end{array}$ & $\begin{array}{c}\text { Thermal diffusivity } \\
\times 10^{-6}\left[\mathrm{~m}^{2} / \mathrm{s}\right]\end{array}$ & $\begin{array}{c}\text { Volumetric heat capacity } \\
\times 10^{6}\left[\mathrm{~J} / \mathrm{m}^{3} \mathrm{~K}\right]\end{array}$ \\
\hline M-R & $1.34 \pm 0.13$ & $0.87 \pm 0.08$ & $1.58 \pm 0.24$ \\
MP 25 & $0.86 \pm 0.08$ & $0.55 \pm 0.06$ & $1.53 \pm 0.22$ \\
MP 50 & $0.48 \pm 0.04$ & $0.32 \pm 0.02$ & $1.49 \pm 0.22$ \\
MP 75 & $0.26 \pm 0.03$ & $0.21 \pm 0.02$ & $1.42 \pm 0.21$ \\
MP 100 & $0.12 \pm 0.01$ & $0.19 \pm 0.01$ & $0.60 \pm 0.09$ \\
\hline
\end{tabular}

TABLE 7. Thermophysical parameters of studied renders. 
than that of the reference render. On the contrary, the low bulk density of perlite-modified renders reduced their heat storage capacity, as show gradually decreasing volumetric heat capacity values.

\section{Summary}

The effect of silica sand substitution by lightweight aggregate on properties of lime-based renders was studied in the paper. Due to the low weight of incorporated perlite mix, the studied renders were markedly lightened. Despite pozzolanic activity of perlite EX 100 , there was recorded decrease in renders mechanical resistance with increasing perlite dosage in render mix. On the other hand, the high porosity of renders resulted in the reduction of heat transport parameters when the measured thermal conductivity of perlitemodified specimens was even eleven times lower than that of the traditional lime-based material. Based on the performed tests and obtained data, it can be concluded, perlite represents lightweight thermoinsulating material suitable for renders prepared by traditional approaches and utilized for renewal or retrofitting purposes.

\section{ACKNOWLEDGEMENTS}

The authors gratefully acknowledge the financial support received from the Czech Science Foundation under project No 18-07332S, and by the CTU in Prague under project No SGS17/166/OHK1/3T/11.

\section{REFERENCES}

[1] A. Arizzi, H. Viles, G. Cultrone. Experimental testing of the durability of lime-based mortars used for rendering historic buildings. Construction and Building Materials 28(1):807-818, 2012. DOI:10.1016/j.conbuildmat.2011.10.059

[2] Y. Govaerts, R. Hayen, M. de Bouw, et al. Performance of a lime-based insulating render for heritage buildings. Construction and Building Materials 159:376-389, 2018. DOI:10.1016/j.conbuildmat.2017.10.115

[3] B. Silva, A. F. Pinto, A. Gomes. Influence of natural hydraulic lime content on the properties of aerial lime-based mortars. Construction and Building Materials 72:208-218, 2014. DOI:10.1016/j.conbuildmat.2014.09.010.

[4] R. Nogueira, A. P. F. Pinto, A. Gomes. Design and behavior of traditional lime-based plasters and renders. Review and critical appraisal of strengths and weaknesses. Cement and Concrete Composites 89:192204, 2018. DOI:10.1016/j.cemconcomp.2018.03.005

[5] EN 998-1 - Specification for mortar for masonry Part 1: Rendering and plastering mortar. Standard, CEN, 2016.

[6] E. Fenoglio, S. Fantucci, V. Serra, et al. Hygrothermal and environmental performance of a perlite-based insulating plaster for the energy retrofit of buildings. Energy and Buildings 179:26-38, 2018. DOI:10.1016/j.enbuild.2018.08.017.
[7] M. Barbero-Barrera, A. García-Santos, F. Neila-González. Thermal conductivity of lime mortars and calcined diatoms. Parameters influencing their performance and comparison with the traditional lime and mortars containing crushed marble used as renders. Energy and Buildings 76:422-428, 2014. DOI:10.1016/j.enbuild.2014.02.065

[8] S. Abidi, B. Nait-Ali, Y. Joliff, C. Favotto. Impact of perlite, vermiculite and cement on the thermal conductivity of a plaster composite material: experimental and numerical approaches. Composites Part B: Engineering 68:392-400, 2015. DOI:10.1016/j.compositesb.2014.07.030

[9] C. Carbonaro, S. Tedesco, F. Thiebat, et al. Development of vegetal based thermal plasters with low environmental impact: optimization process through an integrated approach. Energy Procedia 78:967-972, 2015. DOI:10.1016/j.egypro.2015.11.034.

[10] EN 459-1 - Building lime - Part 1: Definitions, specifications and conformity criteria. Standard, CEN, 2002.

[11] EN 933-1 - Test for geometrical properties of aggregated - Part 1: Determination of particle size distribution - Sieving method. Standard, CEN, 2012.

[12] NF P 18-513 - Pozzolanic Addition for Concrete Metakaolin. Definitions, Specifications and Conformity Criteria. Standard, AFNOR, 2010.

[13] J. Pokornỳ, M. Záleská, M. Pavlíková, Z. Pavlík. Properties of lightweight composite modified by active siliceous admixture. In AIP Conference Proceedings, vol. 1978. AIP Publishing, 2018. DOI:10.1063/1.5043878

[14] EN 196-6 - Methods of testing cement - Part 6: Determination of fineness. Standard, CEN, 2010.

[15] EN 1015-10 - Methods of test for mortar for masonry - Part 10: Determination of dry bulk density of hardened mortar. Standard, CEN, 1999.

[16] M. Pavlíková, L. Zemanová, Z. Pavlík. Thermophysical properties of hydrophobised lime plasters - The influence of ageing. In AIP Conference Proceedings, vol. 1866. AIP Publishing, 2017. DOI:10.1063/1.4994510

[17] EN 1015-11 - Methods of test for mortar for masonry - Part 11: Determination of flexural and compressive strength of hardened mortar. Standard, CEN, 2000.

[18] M. Pavlíková, L. Zemanová, J. Pokorný, et al. Valorization of wood chips ash as an eco-friendly mineral admixture in mortar mix design. Waste Management 80:89-100, 2018. DOI:10.1016/j.wasman.2018.09.004

[19] J. Fořt, A. Trník, D. Čítek, Z. Pavlík. Residual mechanical properties of hybrid fiber reinforced HPC exposed to high temperatures. In Key Engineering Materials, vol. 722, pp. 52-58. Trans Tech Publications, 2017. DOI:10.4028/www.scientific.net/KEM.722.52

[20] M. Pavlíková, L. Zemanová, M. Záleská, et al. Ternary blended binder for production of a novel type of lightweight repair mortarn. Materials 12(6), 2019. DOI:10.3390/ma12060996. 